\title{
Vasopressin Effects on Lung Liquid Volume in Fetal Sheep
}

\author{
JAMES J. CUMMINGS, DAVID P. CARLTON, FRANCIS R. POULAIN, CANDICE D. FIKE, \\ LANNY C. KEIL, AND RICHARD D. BLAND \\ Cardiovascular Research Institute and Department of Pediatrics, University of California San Francisco, \\ San Francisco, California 94143 [F.R.P.], Department of Pediatrics, State University of New York at \\ Buffalo, Buffalo, New York 14222 [J.J.C.], Department of Pediatrics, University of Utah, Salt Lake City, \\ Utah 84132 [D.P.C., C.D.F., R.D.B.], and Space Life Sciences Division, NASA-Ames Research Center, \\ Moffett Field, California 94035 [L.C.K.]
} \begin{abstract}
The normal switch from placental to pulmonary gas exchange
The
at birth requires rapid removal of liquid from the lungs. Previous reports contend that vasopressin may be important in regulating this process, but this notion derives from studies in which fetal sheep received very large doses of vasopressin that yielded plasma concentrations at least 10 times greater than those that have been measured during normal labor. To study the physiologic effects of vasopressin on lung liquid volume in fetal sheep, we made three sets of experiments. First, we measured plasma vasopressin concentrations [VP] in 15 late-gestation fetal sheep, five of which were at various stages of spontaneous labor. [VP] in these fetuses ranged from $<1$ (prelabor) to 31 (during labor) $\mu \mathrm{U} / \mathrm{mL}$; postmortem extravascular lung water (EVLW) ranged from 4.5 to $14.5 \mathrm{~g} / \mathrm{g}$ dry lung tissue. In a second series of studies, we measured EVLW in five sets of near-term $(138 \pm 1 \mathrm{~d}$, term $=147 \mathrm{~d}$ ) twin fetal sheep that received an 8-h i.v. infusion of either isotonic saline (control twin) or AVP (AVP-treated twin) at a rate of $\sim 1(\mathrm{mU} / \mathrm{kg}) / \mathrm{min}$. This dose was chosen to mimic [VP] measured in fetuses that had been studied during labor. [VP] did not change in the control twins, whereas [VP] increased from $1.8 \pm 1.0$ to $27.7 \pm 3.5 \mu \mathrm{U} / \mathrm{mL}$ in treated twins. There was a small, statistically significant difference in EVLW between twins that received AVP and untreated twins $(11.9 \pm 1.8$ versus $14.6 \pm 2.8 \mathrm{~g} / \mathrm{g}$ dry lung). In a third series of studies, we measured
\end{abstract}

During fetal life, the lungs are filled with liquid that forms as a result of epithelial $\mathrm{Cl}^{-}$secretion into the lumen of the developing respiratory tract (1). Rapid removal of this liquid from potential airspaces is an essential step in establishing an effective switch from placental to pulmonary gas exchange at

Received March 15, 1994; accepted March 16, 1995.

Correspondence: Richard D Bland, M.D., University of Utah Health Sciences Center, 50 North Medical Drive, Salt Lake City, UT 84132

Supported by National Heart, Lung, and Blood Institute (NHLBI) Grants HL-27356 (Pulmonary Specialized Center of Research) and HL-40802. J.J.C. received support from National Institutes of Health Training Grant HL-07185; D.P.C. received support from National Institutes of Health Training Grant HD-07162. net production of lung liquid $(\mathrm{Jv})$ by an indicator dilution technique in 16 fetal sheep that received an i.v. infusion of isotonic saline for $2 \mathrm{~h}$ followed by AVP for up to $8 \mathrm{~h}$. [VP] averaged 23.4 $\pm 6.5 \mu \mathrm{U} / \mathrm{mL}$ during AVP infusion. For six fetuses that were studied at $<132 \mathrm{~d}(128 \pm 4 \mathrm{~d})$ gestation, Jv did not change during AVP infusion $(11.1 \pm 6.7 \mathrm{~mL} / \mathrm{h}$ versus control, $10.2 \pm$ $4.7 \mathrm{~mL} / \mathrm{h})$; for 10 fetuses $>132 \mathrm{~d}(135 \pm 2 \mathrm{~d})$ gestation, $\mathrm{Jv}$ decreased from $11.3 \pm 4.7 \mathrm{~mL} / \mathrm{h}$ during the control period to 8.6 $\pm 5.4 \mathrm{~mL} / \mathrm{h}$ during AVP infusion. Net secretion of lung liquid did not switch to net absorption in any of the 16 fetuses that received AVP. Thus, i.v. infusion of AVP, at a rate designed to mimic [VP] measured during spontaneous labor, led to modest reductions in Jv and EVLW, but did not cause net absorption of lung liquid in late-gestation fetal sheep. (Pediatr Res 38: 30-35, 1995)
Abbreviations
[VP], plasma concentration of vasopressin
EVLW, extravascular lung water
$\mathrm{PaO}_{2}, \mathrm{PCO}_{2}$ in arterial blood
$\mathrm{PaCO} 2, \mathrm{PCO}_{2}$ in arterial blood
$\mathbf{J v}$, net production of lung liquid (rate of change in cumulative lung liquid volume over time)

birth. There is abundant evidence that this process of liquid clearance normally begins before birth and is driven by active transepithelial sodium flux toward the lung interstitium $(2,3)$, with subsequent absorption of liquid into the pulmonary circulation and lymphatics (4). What regulates this process remains unclear, but several studies have suggested that a birthrelated release of specific hormones, notably epinephrine (5) and vasopressin (6-8), into the fetal circulation may contribute to rapid absorption of liquid from the lungs before airbreathing begins.

Published reports concerning the effects of vasopressin on lung liquid removal describe studies conducted with fetal sheep 
and goats not during birth, but during i.v. infusion of AVP in the last month of gestation (6-11). Some studies have shown that the inhibitory effect of AVP on fetal lung liquid production is gestation-dependent, with little or no effect before $\sim 130 \mathrm{~d}$ $($ term $=147 \mathrm{~d})$ gestation $(6,7)$. With increasing fetal maturation, however, i.v. infusion of AVP consistently reduces net production of lung liquid and sometimes leads to liquid absorption late in gestation in the presence of labor. One study also showed a synergistic effect of epinephrine and AVP in reducing net production of lung liquid in fetal goats near term (6). In these studies, the inhibitory dose of AVP was sufficient to yield plasma concentrations of the hormone that were at least 10 times greater than those that have been measured in sheep during normal spontaneous labor and delivery $(12,13)$. Moreover, a recent report showed that AVP had no significant effect on the bioelectric properties of confluent monolayers of cultured lung epithelial cells harvested from late-gestation fetal rats (14). Thus, the importance of vasopressin in regulating lung liquid clearance near birth is uncertain.

The goal of this work was to determine the effects of i.v. infusion of AVP, at a dose designed to produce plasma concentrations approximating those that are measured during normal spontaneous labor, on the rate of production of lung liquid and on the amount of extravascular water in the lungs of fetal sheep late in gestation. We found that i.v. infusion of AVP had only a modest inhibitory effect on net production of lung liquid and on extravascular lung water content. These infusions did not induce net absorption of lung liquid in any of the sheep that we studied.

\section{METHODS}

Surgical preparation. By methods previously described, we surgically prepared 44 fetal lambs with chronic vascular catheters; 19 of these lambs also had a large-bore loop catheter that was inserted into the trachea for measurement of net lung liquid production, as described by Chapman et al. $(15,16)$. Time-dated pregnant ewes underwent surgery at 121-134 d of gestation. The sheep received ketamine, $500 \mathrm{mg}$ intramuscularly, followed by either spinal anesthesia with $1 \%$ tetracaine, or general anesthesia with $1 \%$ halothane and nitrous oxide delivered with supplemental oxygen by a piston-type ventilator. We opened the uterus through a midline abdominal incision and exposed the fetal head and neck. If the ewe had received spinal anesthesia, we injected $1 \%$ lidocaine s.c. into the skin of the fetal neck, after which we inserted polyvinyl catheters into the carotid artery and jugular vein. In 19 fetuses, we incised the fetal trachea and inserted both ends of a saline-filled silicone rubber catheter (Silastic medical grade tubing, Dow Corning, Midland, MI; outside diameter $5.0 \mathrm{~mm}$, inside diameter $2.6 \mathrm{~mm}$, volume $17 \mathrm{~mL}$ ). One end of this catheter was positioned just above the tracheal bifurcation and the other end just below the vocal cords, leaving a loop of catheter outside the fetus. We placed a smaller polyvinyl catheter (outside diameter $2.3 \mathrm{~mm}$, inside diameter $1.3 \mathrm{~mm}$ ) in the lumen of the distal trachea for subsequent pressure monitoring. The trachea was closed tightly around both catheters so that liquid flowed from the lungs through the catheter loop and back into the upper airway. All fetuses had a catheter sutured to the outside of the neck, with the tip of the catheter in the amniotic sac, providing a zero reference for subsequent pressure measurements. Skin incisions were closed and all catheters were tunneled through the uterine and abdominal walls, which were doubly oversewn to prevent fluid leakage. A pouch was sewn to the maternal flank to protect the catheters from damage.

We injected antibiotics into the amniotic sac $\left(10^{6} \mathrm{U}\right.$ penicillin and $400 \mathrm{mg}$ kanamycin) and fetal vein $(300,000 \mathrm{U}$ penicillin and $30 \mathrm{mg}$ kanamycin) at the time of surgery and daily thereafter. Vascular catheters were flushed with isotonic saline and filled with heparin $(1,000 \mathrm{U} / \mathrm{mL})$ daily. All operative procedures and experimental protocols were approved by the Committee on Animal Use at the University of California San Francisco.

Experimental protocol. Sheep were allowed to recover from surgery for at least $3 \mathrm{~d}$ before experiments began. Studies were done on unanesthetized fetuses that were judged to be healthy by arterial $\mathrm{pH}$ and blood gas tensions. The fetuses were studied while their ewes stood upright in a cage with free access to food and water. In 15 late-gestation fetuses, we obtained samples of fetal blood for measurement of [VP]; five of these fetuses were in active labor that was detected by the presence of regular and repetitive increases in amniotic liquid pressure that varied from 5 to $20 \mathrm{~mm} \mathrm{Hg}(0.7-2.7 \mathrm{kPa})$. Samples of plasma were obtained by centrifugation of blood specimens, after which they were frozen at $-80^{\circ} \mathrm{C}$. Ewes in labor were killed with an i.v. overdose of sodium pentobarbital, and the fetal lungs were immediately removed for measurement of EVLW as described below. In the two sets of vasopressin infusion studies, we measured fetal arterial $\mathrm{pH}, \mathrm{PaO}_{2}$, and $\mathrm{PaCO}_{2}$ hourly with a calibrated blood gas/acid-base analyzer (model 158, Corning, Medfield, MA). We continuously measured arterial, venous, tracheal, and amniotic liquid pressures with calibrated transducers (Statham BT3DC and 131TC; Statham Instruments, Oxnard, CA) connected to an eight-channel amplifier-recorder (model 7D polygraph, Grass Instruments, Quincy, MA). Vascular and tracheal pressures were expressed relative to amniotic liquid pressure. All variables were measured during a 2 - $h$ baseline period (in which the vasopressin vehicle was infused) and throughout the i.v. vasopressin infusion, which lasted 2-8 h.

In studies designed to measure lung liquid production over time, samples of lung liquid were withdrawn at 10-min intervals to determine the rate of lung liquid production, as described below. We also did seven control experiments of lung liquid production for up to $10 \mathrm{~h}$, in which the fetuses received no drugs.

Measurement of [VP]. We obtained samples of arterial blood in chilled, heparin-coated syringes, and the blood samples were immediately spun at $4^{\circ} \mathrm{C}$. The plasma was withdrawn and stored at $-80^{\circ} \mathrm{C}$ for $2-6 \mathrm{wk}$ until extraction and assay by the method of Skowsy et al. (17). Briefly, vasopressin was extracted by absorption onto bentonite, followed by elution with acetone and separation with a 50:50 mixture of acetone:petroleum ether. The dried specimens were sealed and transferred to an independent laboratory (NASA-Ames Re- 
search Center, Moffet Field, CA), where the samples were reconstituted and [VP] measured by RIA. The assay has a coefficient of variation of $\sim 7 \%$ for intraassay measurements and $\sim 15 \%$ for interassay measurements (17).

$\boldsymbol{A V P}$ infusion studies. Fetuses first received a 2-h i.v. infusion of vehicle at the beginning of each experiment (control period). The vehicle was a solution of chlorbutanol, $1 \mu \mathrm{L} / \mathrm{mL}$ of isotonic saline, that was infused at a rate of $10 \mathrm{~mL} / \mathrm{h}$. This 2-h control period was followed by an i.v. infusion of AVP for 2-8 h. A stock solution $(20 \mathrm{U} / \mathrm{mL}$ of isotonic solution with chlorbutanol, $1 \mu \mathrm{L} / \mathrm{mL}$ ) of AVP (Quad, Indianapolis, IN) was diluted in isotonic saline to a concentration of $16-20 \mathrm{mU} / \mathrm{mL}$ for infusion into the fetal vein at a rate of $10 \mathrm{~mL} / \mathrm{h}$. This was calculated to achieve a vasopressin dose of $\sim 1(\mathrm{mU} / \mathrm{kg}) / \mathrm{min}$ for an estimated fetal weight of $2.8-3.5 \mathrm{~kg}$ at $128-139 \mathrm{~d}$ of gestation. This dose was selected on the basis of our previous work in fetal lambs which indicated that a vasopressin infusion rate of $1(\mathrm{mU} / \mathrm{kg}) / \mathrm{min}$ would yield steady-state plasma concentrations of $15-30 \mu \mathrm{U} / \mathrm{mL}$ (18), comparable to levels measured during spontaneous labor $(12,13)$.

Measurement of lung liquid production. We measured $\mathrm{JV}$ by an indicator dilution method that was previously described by Walters and Olver (19) and modified by Chapman et al. (15, 16). At the start of each experiment, the tracheal loop was cut at its midpoint and lung liquid was withdrawn into a large, warm syringe to permit mixing and withdrawal of samples. We injected into the lung liquid a radiolabeled tracer $\left({ }^{125} \mathrm{I}\right.$ human serum albumin, Mallinckrodt Inc., St. Louis, MO) that does not penetrate the epithelium, and we mixed the tracer in the liquid by gentle withdrawal and infusion several times over a 20-min period. Tracheal pressure did not exceed $20 \mathrm{~cm} \mathrm{H}_{2} \mathrm{O}(2.0 \mathrm{kPa})$ during this mixing procedure. We then removed $1-2 \mathrm{~mL}$ samples of lung liquid every $10 \mathrm{~min}$ for the duration of the experiment and measured the radioactivity ( $\gamma$ counter, Beckman Instruments, Palo Alto, CA) in duplicate $100-\mu \mathrm{L}$ aliquots of each liquid sample. Gentle withdrawal and reinfusion of lung liquid was repeated between liquid samplings to assure uniform distribution of the albumin tracer within the lung lumen. The size of each liquid sample was adjusted to keep luminal liquid volume nearly constant. We obtained plasma samples periodically to assure that the albumin tracer remained within the lung lumen over the time course of these experiments; there was no detectable radioactivity in plasma. We made 23 experiments using 19 fetuses. Fetuses that were studied more than once had samples of lung liquid taken at the start of each subsequent experiment to measure background radioactivity in the lung liquid. After instillation of fresh radiolabeled tracer, sequential radioactive counts were adjusted by subtracting the background count for each sample.

Extravascular lung water measurements. At the end of some of the experiments, we inserted copper plugs into the vascular catheters and performed spinal anesthesia with $1 \%$ tetracaine on the ewe to deliver the fetus by cesarean section. We then injected a lethal i.v. dose of sodium pentobarbital, 25 $\mathrm{mg} / \mathrm{kg}$, rapidly split the sternum, occluded the trachea to prevent loss of lung liquid, aspirated blood from the heart, and clamped both hili. The lungs were resected, homogenized, and the amount of extravascular water was determined by a gravimetric technique (20).

Data analysis. We calculated the volume of liquid within the lung lumen at the start of each experiment by determining the concentration of ${ }^{125}$ I-albumin after thorough mixing. We then calculated the cumulative volume of lung liquid at each time point based on the dilution of ${ }^{125} \mathrm{I}$-albumin, with appropriate corrections for the radioactivity and liquid volumes removed in previous samples. We calculated by least squares regression analysis the rate of change in cumulative lung liquid volume over time (Jv). Jv represents the sum of liquid secretion and absorption, processes that may coexist in different regions within the respiratory tract. A positive value for $\mathrm{Jv}$ indicates net production, a negative value represents net absorption.

Statistics. Results are expressed as mean values $\pm 1 \mathrm{SD}$. We used a paired $t$ test to compare data obtained from fetuses before and during AVP infusion; we used an unpaired $t$ test to compare data obtained from fetuses that received i.v. saline infusion versus those that received AVP, and to compare fetuses with and without labor. We defined as statistically significant those differences that were supported by a $p$ value of $<0.05$.

\section{RESULTS}

Studies of fetal lambs with and without labor. Arterial blood samples were obtained from 15 fetal lambs at 136-144 $\mathrm{d}$ of gestation. There were no significant differences between fetuses with or without labor with respect to arterial $\mathrm{pH}$ and blood gas tensions (data not shown). In the initial series of studies designed to determine [VP] in fetal sheep before and during labor, [VP] averaged $0.9 \pm 0.6 \mu \mathrm{U} / \mathrm{mL}$ (range: $0-2.8$ $\mu \mathrm{U} / \mathrm{mL}$ ) and EVLW averaged $12.3 \pm 0.8 \mathrm{~g} / \mathrm{g}$ dry lung (range: 9.9-14.7 $\mathrm{g} / \mathrm{g}$ dry lung excluding blood) for 10 fetuses that were killed without labor. In five fetuses that were killed during spontaneous labor, [VP] averaged $11.1 \pm 11.6 \mu \mathrm{U} / \mathrm{mL}$ (range: $3.4-31.0 \mu \mathrm{U} / \mathrm{mL}$ ), and EVLW averaged $6.5 \pm 1.5 \mathrm{~g} / \mathrm{g}$ dry lung (range: $4.5-8.6 \mathrm{~g} / \mathrm{g}$ dry lung).

Studies of EVLW in twin fetuses \pm i.v. AVP infusion. Five pairs of twin lambs were studied at $138 \pm 1 \mathrm{~d}$ of gestation. There were no significant differences between saline-treated and AVP-treated fetuses with respect to arterial $\mathrm{pH}$ and blood gas tensions (data not shown). Compared with saline-treated controls, AVP infusion caused significant increases of [VP] and arterial blood pressure, and a significant decrease in heart rate (Table 1). Body weight was similar for saline-treated and AVP-treated twins $(2.9 \pm 0.4 \mathrm{~kg})$, and EVLW was signifcantly less in the fetuses that received AVP (11.9 \pm 1.8 versus $14.6 \pm 2.8 \mathrm{~g} / \mathrm{g}$ dry lung tissue for control fetuses).

Studies of net lung liquid production. In seven control experiments performed with fetuses (131 $\pm 3 \mathrm{~d}$ of gestation) that received i.v. saline for up to $10 \mathrm{~h}$, there was no change in $\mathrm{JV}_{\mathrm{V}}$ between the first and last $2 \mathrm{~h}$ of study, nor were there significant changes in any of the measured variables over time in these seven studies (Table 2).

The i.v. infusion of AVP did not alter Jv in fetuses $<132 \mathrm{~d}$ of gestation, but Jv decreased on average by $24 \%$ during AVP infusion in fetuses $>132 \mathrm{~d}$ of gestation (Table 2). For the six 
Table 1. Data from studies in which five sets of twin fetal sheep (gestation $138 \pm 1$ d) received i.v. infusions of either isotonic saline or

\begin{tabular}{|c|c|c|c|c|c|c|}
\hline Fetuses & Period & $\begin{array}{l}\text { Body weight } \\
(\mathrm{kg})\end{array}$ & $\begin{array}{l}\text { Mean arterial blood } \\
\text { pressure }(\mathrm{kPa})\end{array}$ & $\begin{array}{l}\text { Heart rate } \\
\text { (beats/min) }\end{array}$ & $\begin{array}{c}{[\mathrm{VP}]} \\
(\mu \mathrm{U} / \mathrm{ml})\end{array}$ & $\begin{array}{c}\text { EVLW } \\
\text { (g/g dry lung) }\end{array}$ \\
\hline Control & $\begin{array}{l}\text { Baseline } \\
\text { Saline infusion }\end{array}$ & $2.75 \pm 0.36$ & $\begin{array}{l}7.5 \pm 0.8 \\
7.2 \pm 0.5\end{array}$ & $\begin{array}{l}171 \pm 23 \\
170 \pm 25\end{array}$ & $\begin{array}{l}1.9 \pm 0.6 \\
2.6 \pm 1.5\end{array}$ & $14.6 \pm 2.8$ \\
\hline AVP & $\begin{array}{l}\text { Baseline } \\
\text { AVP infusion }\end{array}$ & $2.87 \pm 0.45$ & $\begin{array}{l}7.1 \pm 0.3 \\
8.0 \pm 0.8 * \dagger\end{array}$ & $\begin{array}{l}165 \pm 11 \\
145 \pm 16^{*} \dagger\end{array}$ & $\begin{array}{c}1.6 \pm 0.9 \\
27.3 \pm 7.4^{*} \dagger\end{array}$ & $11.9 \pm 1.8 \dagger$ \\
\hline
\end{tabular}

Values are mean $\pm \mathrm{SD}$; to convert $\mathrm{kPa}$ to $\mathrm{mm} \mathrm{Hg}$, multiply by 7.5 .

* Significant difference compared to baseline period, $p<0.05$.

$\dagger$ Significant difference compared to fetuses that received i.v. saline, $p<0.05$.

Table 2. Data from studies in which $J v$ was measured in fetal lambs that received i.v. infusion of either vehicle (control) or AVP

\begin{tabular}{|c|c|c|c|c|c|c|c|c|}
\hline Fetuses & Number & Period & $\begin{array}{l}\text { Gestation } \\
\text { (d) }\end{array}$ & $\begin{array}{l}\text { Initial lung liquid } \\
\text { volume (ml) }\end{array}$ & $\begin{array}{c}\text { Mean arterial blood } \\
\text { pressure }(\mathrm{kPa})\end{array}$ & $\begin{array}{c}\text { Heart rate } \\
\text { (beats/min) }\end{array}$ & $\begin{array}{c}{[\mathrm{VP}] \ddagger} \\
(\mu \mathrm{U} / \mathrm{ml})\end{array}$ & $\begin{array}{c}\mathrm{JV}_{\mathrm{V}} \\
(\mathrm{ml} / \mathrm{min}) \\
\end{array}$ \\
\hline Control & 7 & $\begin{array}{l}\text { Baseline } \\
\text { Vehicle infusion }\end{array}$ & $131 \pm 3$ & $98 \pm 23$ & $\begin{array}{l}7.0 \pm 0.9 \\
7.0 \pm 0.9\end{array}$ & $\begin{array}{l}173 \pm 27 \\
173 \pm 22\end{array}$ & & $\begin{array}{l}13.0 \pm 2.4 \\
13.0 \pm 2.9\end{array}$ \\
\hline $\begin{array}{l}\text { AVP } \\
(<132 \text { d })\end{array}$ & 6 & $\begin{array}{l}\text { Baseline } \\
\text { AVP infusion }\end{array}$ & $128 \pm 2$ & $102 \pm 25$ & $\begin{array}{l}6.4 \pm 1.1 \\
7.5 \pm 1.1^{*}\end{array}$ & $\begin{array}{l}177 \pm 12 \\
159 \pm 11^{*}\end{array}$ & $\begin{aligned} 6.1 & \pm 5.0 \\
25.8 & \pm 4.2^{*}\end{aligned}$ & $\begin{array}{l}10.2 \pm 4.7 \\
11.1 \pm 6.7\end{array}$ \\
\hline $\begin{array}{l}\text { AVP } \\
(>132 d)\end{array}$ & 10 & $\begin{array}{l}\text { Baseline } \\
\text { AVP infusion }\end{array}$ & $135 \pm 2$ & $107 \pm 26$ & $\begin{array}{l}6.7 \pm 0.8 \\
7.5 \pm 1.1^{*}\end{array}$ & $\begin{array}{l}169 \pm 20 \\
138 \pm 23^{*} \dagger\end{array}$ & $\begin{array}{c}6.0 \pm 4.4 \\
22.4 \pm 7.4^{*}\end{array}$ & $\begin{array}{r}11.3 \pm 4.7 \\
8.6 \pm 5.4^{*}\end{array}$ \\
\hline
\end{tabular}

Values are mean $\pm \mathrm{SD}$; to convert $\mathrm{kPa}$ to $\mathrm{mm}$ Hg pressure, multiply by 7.5 .

* Significant difference compared to baseline period, $p<0.05$.

$\dagger$ Significant difference compared to control fetuses, $p<0.05$.

$\ddagger[\mathrm{VP}]$ measured in three fetuses $<132 \mathrm{~d}$ and seven fetuses $>132 \mathrm{~d}$ of gestation.

fetuses that were studied at a gestational age of $<132 \mathrm{~d}(128 \pm$ $2 \mathrm{~d}), \mathrm{Jv}$ averaged $10.2 \pm 4.7 \mathrm{~mL} / \mathrm{h}$ during the control period and $11.1 \pm 6.7 \mathrm{~mL} / \mathrm{h}$ during AVP infusion. For the 10 fetuses that were studied at a gestational age of $>132 \mathrm{~d}(135 \pm 2 \mathrm{~d})$, $\mathrm{Jv}$ averaged $11.3 \pm 4.7 \mathrm{~mL} / \mathrm{h}$ during the control period and 8.6 $\pm 5.4 \mathrm{~mL} / \mathrm{h}$ during AVP infusion.

Mean arterial blood pressure increased $(6.6 \pm 0.8$ to $7.5 \pm$ $1.1 \mathrm{kPa})$ and heart rate decreased $(172 \pm 17$ to $145 \pm 22$ beats/min) significantly during AVP infusion. These changes were consistent irrespective of gestational age. There were no significant changes in arterial $\mathrm{pH}$ or blood gas tensions associated with AVP infusion (data not shown). We obtained paired arterial blood samples before and during AVP infusion in 10 of the 16 experiments: [VP] averaged $6.0 \pm 4.3 \mu \mathrm{U} / \mathrm{mL}$ during the control period and $23.4 \pm 6.5 \mu \mathrm{U} / \mathrm{mL}$ during AVP infusion.

\section{DISCUSSION}

The importance of a hormone in regulating a body function depends on its action at normal physiologic concentrations. The results of our studies indicate that i.v. infusion of AVP, at a rate designed to mimic plasma concentrations measured during normal labor, causes small but significant decreases in both lung liquid production and extravascular lung water in late-gestation fetal sheep. Net absorption of lung liquid did not occur in any of our vasopressin infusion experiments. However, we cannot exclude the possibility that vasopressin might have a role in removing liquid from the lungs during normal spontaneous labor at term gestation, where the role of epinephrine remains controversial $(4,5,16,21)$.

Several reports have shown that umbilical cord [VP] increases at birth both in human infants (22-27) and newborn sheep $(12,13,28)$. Values are greatest after spontaneous vaginal delivery. Previous studies showed that [VP] in lategestation fetal sheep averaged $<10 \mu \mathrm{U} / \mathrm{mL}$ and increased up to 5 -fold during spontaneous labor, with plasma concentrations in umbilical cord blood averaging 10-30 $\mu \mathrm{U} / \mathrm{mL}(12,13,28)$.

These observations provided the rationale for several groups of investigators to test the effects of AVP on lung liquid production in fetal goats and sheep (6-11). Perks and Cassin (9) infused AVP i.v. into fetal goats at a rate of 1.6-39.2 $(\mathrm{mU} / \mathrm{kg}) / \mathrm{min}$ for 1 or $2 \mathrm{~h}$. Five fetuses $<127 \mathrm{~d}$ of gestation showed no response in lung liquid production, whereas 16 fetuses $>131 \mathrm{~d}$ of gestation had progressive reduction in lung liquid secretion, with net liquid absorption in some of the fetuses. These were acute studies conducted in the presence of anesthesia immediately after surgery, conditions that may stimulate endogenous release of vasopressin $(12,22)$ and other stress-related hormones, including catecholamines. These authors estimated a threshold effect on lung liquid production that became evident at an infusion rate of $\sim 1.3(\mathrm{mU} / \mathrm{kg}) / \mathrm{min}$, similar to the rate that we used in our studies. The same investigators also studied eight chronically catheterized fetal sheep and found that i.v. infusion of AVP decreased lung liquid secretion in four fetuses $>134 \mathrm{~d}$ of gestation (29). In these studies, however, the rate of infusion of AVP was 7.5-20.5 $(\mathrm{mU} / \mathrm{kg}) / \mathrm{min}$, several times greater than the rate of infusion that we used. These investigators found that the effect of AVP infusion on lung liquid production was both dose- and gestation-dependent $(6,29)$.

In their 1979 report on [VP] in fetal sheep before and during spontaneous vaginal delivery, Stark et al. (13) found that [VP] averaged $2 \pm 3 \mathrm{pg} / \mathrm{mL}(1 \mathrm{pg}=0.36 \mu \mathrm{U}$; AVP units may vary according to the specific preparation that is used) on the day 
before delivery, whereas [VP] measured during labor in four fetuses averaged $\sim 21 \mathrm{pg} / \mathrm{mL}$, increasing to $26 \mathrm{pg} / \mathrm{mL}$ in umbilical cord blood. This report included the results from one additional fetal sheep, in which [VP] was $4,667 \mathrm{pg} / \mathrm{mL}$ during labor and $8,000 \mathrm{pg} / \mathrm{mL}$ in umbilical cord blood. This animal had severe respiratory distress from birth and died $3 \mathrm{~h}$ after delivery. The authors noted that [VP] measured in this preterm lamb was comparable to plasma concentrations measured in portal hypophyseal blood. This animal was atypical on several counts: it was premature, measurements of [VP] before labor were not recorded, death occurred within $3 \mathrm{~h}$ of birth, and [VP] measured during labor and in cord blood were clearly aberrant from other published values during labor. Yet the data reported for this single animal subsequently served as rationale for infusing large doses of vasopressin into otherwise healthy fetal sheep to determine their "physiologic response" in terms of lung liquid production. For example, Wallace et al. (7) infused AVP at a dose of $300(\mathrm{mU} / \mathrm{kg}) / \mathrm{h}$ for $2 \mathrm{~h}$ and reported plasma concentrations that averaged $849 \pm 75 \mathrm{pg} / \mathrm{mL}$, a dose that was sufficient to induce lung liquid absorption in fetal sheep close to term gestation. Cassin and Perks (8) infused AVP at a rate that averaged almost $1500(\mathrm{mU} / \mathrm{kg}) / \mathrm{h}$ for $7 \mathrm{~h}$, and although they did not measure plasma concentrations in these fetal sheep, it is likely that they were at least as great as the plasma concentrations measured by Wallace et al. (7). In these studies, prolonged infusion of AVP at this very high dose substantially inhibited lung liquid production and in some cases led to liquid absorption; intrapulmonary administration of amiloride, an inhibitor of conductive sodium transport, reversed this effect $(8,11)$. Because plasma concentrations in these animals were at least 10 times greater than those measured during normal labor in sheep, the physiologic significance of these studies remains uncertain.

Are there other data to support the use of such high doses of AVP in these earlier studies? A number of investigators have shown that plasma concentrations of vasopressin may increase significantly in fetal sheep that undergo the stress of severe hypoxemia $(30,31)$, hemorrhage $(32)$, or premature labor induced by i.v. infusion of ACTH (33). Moreover, [VP] measurements in umbilical cord blood of vaginally delivered human infants are considerably greater than they are in fetal sheep $(22-26,34,35)$. Values are greater in umbilical arterial than in umbilical venous blood, with plasma concentrations sometimes in excess of $600 \mu \mathrm{U} / \mathrm{mL}(25,34,35)$.

In our studies, we chose an i.v. infusion rate of AVP that would increase plasma concentrations to $20-30 \mu \mathrm{U} / \mathrm{mL}$, comparable to those that we and others have measured during labor. These infusions caused only modest decreases in lung liquid production and extravascular lung water of fetal sheep late in gestation. It is possible, however, that plasma concentrations of vasopressin measured in fetal sheep during spontaneous labor might contribute to clearance of lung liquid if there is an increase in the sensitivity of the epithelium to vasopressin at this later stage of lung development. This notion is analogous to the increased lung epithelial sensitivity to epinephrine that may develop in sheep during labor, wherein sodium and liquid absorption may occur even at plasma concentrations of epinephrine that are within the normal prelabor range (5). In addition, the higher [VP] measured in umbilical cord blood of human infants raises the possibility that the aforementioned studies of high dose AVP infusions in fetal sheep might be relevant to lung liquid changes near birth in human infants, provided the human respiratory epithelium is sensitive to vasopressin.

The mechanism by which vasopressin decreases net production of luminal liquid in the fetal lung remains unclear. The i.v. infusion of AVP increases systemic and pulmonary arterial pressures $(30,36)$, which in turn could influence vascular filtration pressure. It is unlikely, however, that this hemodynamic change would affect liquid secretion by the respiratory epithelium, as we and others have shown that this active secretory process is unresponsive to modest changes in vascular filtration pressure $(1,37)$. The observation that intrapulmonary administration of amiloride reversed the inhibitory effect of AVP on lung liquid production led Cassin and Perks (8) to speculate that AVP may act by stimulating $V_{2}$ receptors in lung epithelium, with a resultant increase in adenylate cyclase and protein kinase A activity, culminating in activation of sodium channels on the luminal surface of the epithelium. Increased sodium uptake would be expected to stimulate $\mathrm{Na}^{+}-\mathrm{K}^{+}$. ATPase on the abluminal surface of the epithelium, thereby driving liquid from the airspaces into the interstitium. This proposed mechanism is consistent with the observation by Goodman et al. (38) that AVP increased dome formation in confluent monolayers of cultured lung epithelial cells from adult rats. Contrary to this view, however, three other groups of investigators found no effect of AVP on the bioelectric properties of respiratory epithelium from fetal and adult rats (14, 39 ) and from mature rabbits (40). These observations support the skepticism expressed in a recent commentary on the possible role of vasopressin in stimulating lung liquid clearance by a sodium-dependent process at birth (41).

It is possible that i.v. infusion of AVP may cause release of epinephrine, which is thought to stimulate sodium uptake and liquid absorption by the pulmonary epithelium during and after birth $(3,5)$. This notion is certainly plausible in the setting of prolonged i.v. infusion of AVP at very high doses that are sufficient to induce stress. Nor can we exclude the possibility that AVP acts primarily on transmembrane water channels, rather than sodium channels, of respiratory epithelium, similar to the mechanism that has been described for AVP's action on other epithelia (42). Thus, the specific role of vasopressin in lung liquid clearance at birth is ill-defined and warrants further inquiry.

Acknowledgments. The authors thank A. Westgate and R. Shanks for technical assistance, and S. Marron for typing the manuscript.

\section{REFERENCES}

1. Olver RE, Strang LB 1974 Ion fluxes across the pulmonary epithelium and the secretion of lung liquid in the foetal lamb. J Physiol 241:327-357

2. Bland RD 1990 Lung epithelial ion transport and fluid movement during the perinatal period. Am J Physiol 259:L30-L37

3. Strang L 1991 Fetal lung liquid: secretion and reabsorption. Physiol Rev 71:991-1016

4. Bland RD, Hansen TN, Haberkern CM, Bressack MA, Hazinski TA, Raj JU, Goldberg RB 1982 Lung fluid balance in lambs before and after birth. J Appl Physiol 53:992-1004 
5. Brown MJ, Olver RE, Ramsden CA, Strang LB, Walters DV 1983 Effects of adrenaline and of spontaneous labour on the secretion and absorption of lung liquid in the fetal lamb. J Physiol 344:137-152

6. Perks AM, Cassin S 1989 The effects of arginine vasopressin and epinephrine on lung liquid production in fetal goats. Can J Physiol Pharmacol 67:491-498

7. Wallace MJ, Hooper SB, Harding R 1990 Regulation of lung liquid secretion by arginine vasopressin in fetal sheep. Am J Physiol 258:R104-R111

8. Cassin S, Perks AM 1993 Amiloride inhibits arginine vasopressin-induced decrease in fetal lung liquid secretion. J Appl Physiol 75:1925-1929

9. Perks AM, Cassin S 1982 The effects of arginine vasopressin and other factors on the production of lung liquid in fetal goats. Chest $81: 63 \mathrm{~S}-65 \mathrm{~S}$

10. Ross MG, Ervin G, Leake RD, Fu P, Fisher DA 1984 Fetal lung liquid regulation by neuropeptides. Am J Obstet Gynecol 150:421-425

11. Hooper SB, Wallace MJ, Harding R 1993 Amiloride blocks the inhibition of fetal lung liquid secretion caused by AVP but not by asphyxia. J Appl Physiol 74:111-115

12. Alexander D, Bashore R, Britton H, Forsling M 1974 Maternal and fetal arginine vasopressin in the chronically catheterised sheep. Biol Neonate 25:242-248

13. Stark RI, Daniel SS, Husain KM, James LS, Van de Wiele RL 1979 Arginine vasopressin during gestation and parturition in fetal sheep. Biol Neonate 35:235-241

14. O'Brodovich H, Rafii B, Perlon T 1992 Arginine vasopressin and atrial natriuretic peptide do not alter ion transport by cultured fetal distal lung epithelium. Pediatr Res 31:318-322

15. Chapman DL, Carlton DP, Cummings JJ, Poulain FR, Bland RD 1991 Intrapulmonary terbutaline and aminophylline decrease lung liquid in fetal lambs. Pediatr Res 29:357-361

16. Chapman DL, Carlton DP, Nielson DW, Cummings JJ, Poulain FR, Bland RD 1994 Changes in lung liquid during spontaneous labor in fetal sheep. J Appl Physiol 76:523-530

17. Skowsy W, Rosenbloom A, Fisher D 1974 Radioimmunoassay measurement of arginine vasopressin in serum: development and application. J Clin Endocrinol Metab 38:278-287

18. Bland RD, Fike CD, Teague WG, Braun D, Keil LC 1985 Vasopressin decreases lung water in fetal lambs. Pediatr Res 19:399A(abstr)

19. Walters DV, Olver RE 1978 The role of catecholamines in lung liquid absorption at birth. Pediatr Res 12:239-242

20. Pearce ML, Yamashita J, Beazell J 1965 Measurement of pulmonary edema. Circ Res $16: 482-488$

21. McDonald JV, Gonzales LW, Ballard PL, Pitha J, Roberts JM $1986 \beta$-adrenergic blockade affects perinatal surfactant release but not lung water. J Appl Physiol 60:1727-1733

22. Hoppenstein J, Miltenberger F, Moran W 1968 The increase in blood levels of vasopressin in infants during birth and surgical procedures. Surg Gynecol Obstet 127:966-974

23. Chard T, Hudson C, Edwards C, Boyd N 1971 Release of oxytocin and vasopressin by the human foetus during labour. Nature 234:352-354

24. Hadeed A, Leake R, Weitzman R, Fisher D 1979 Possible mechanisms of high blood levels of vasopressin during the neonatal period. J Pediatr 94:805-808
25. Pohjavuori M, Fyhrquist $F 1980$ Hemodynamic significance of vasopressin the newborn infant. J Pediatr 97:462-465

26. Parboosingh J, Lederis K, Singh N 1982 Vasopressin concentration in cord blood: correlation with method of delivery and cord pH. Obstet Gynecol 60:179-183

27. Pochard J, Lutz-Bucher B 1986 Vasopressin and oxytocin levels in human neonates. Acta Paediatr Scand 75:774-778

28. Leffler CW, Crofton J, Brooks DP, Share L, Hessler JR, Green RS 1985 Changes in plasma arginine vasopressin during transition from fetus to newborn following minimal trauma delivery of lambs and goats. Biol Neonate 48:43-48

29. Perks A, Cassin S 1985 The effects of arginine vasopressin on lung liquid secretion in chronic fetal sheep. In: Jones C (ed) The Physiological Development of the Fetus and Newborn. Academic Press, London, pp 303-329

30. Rurak D 1978 Plasma vasopressin levels during hypoxaemia and cardiovascular effects of exogenous vasopressin in foetal and adult sheep. J Physiol 277:341-357

31. Stark R, Wardlaw S, Daniel S, Husain M, Sanocka U, James L, Van de Wiele R 1982 Vasopressin secretion induced by hypoxia in sheep: Developmental changes and relationship to $\beta$-endorphin release. Am J Obstet Gynecol 143:204-213

32. Drummond W, Rudolph A, Keil L, Gluckman P, McDonald A, Heymann M 1980 Arginine vasopressin and prolactin after hemorrhage in the fetal lamb. Am J Physiol 238:E214-E219

33. Stark RI, Daniel SS, Husain MK, Milliez J, Morishima HO, James LS, Van de Wiele RL 1981 Release of vasopressin by the fetal lamb during premature parturition induced with corticotropin. Pediatr Res 15:1261-1265

34. Polin R, Husain M, James L, Frantz A 1977 High vasopressin concentrations in human umbilical cord blood-lack of correlation with stress. J Perinatol Med 5:114-119

35. Leung A, McArthur R, McMillan D, Ko D, Deacon J, Parboosingh J, Lederis K 1980 Circulating antidiuretic hormone during labour and in the newborn. Acta Paediatr Scand 69:505-510

36. Iwamoto H, Rudolph A, Keil L, Heymann M 1979 Hemodynamic responses of the sheep fetus to vasopressin infusion. Circ Res 44:430-436

37. Carlton DP, Cummings JJ, Poulain FR, Bland RD 1992 Increased pulmonary vascular filtration pressure does not alter lung liquid secretion in fetal sheep. J Appl Physiol 72:650-655

38. Goodman BE, Brown SES, Crandall ED 1984 Regulation of transport across pulmonary alveolar epithelial cell monolayers. J Appl Physiol 57:703-710

39. Cott G, Sugahara K, Mason R 1986 Stimulation of net active ion transport across type II cell monolayers. Am J Physiol 250:C222-C227

40. Boucher R, Gatzy J 1983 Characteristics of sodium transport by excised rabbit trachea. J Appl Physiol 55:1877-1883

41. Strang L, Barker P 1993 Amiloride inhibits arginine vasopressin-induced decrease in fetal lung liquid secretion (editorial). J Appl Physiol 75:1923-1924

42. Wade J, Stetson D, Lewis S 1981 ADH action: Evidence for a membrane shuttle mechanism. Ann NY Acad Sci 1981:106-116 